\title{
Delay to celiac disease diagnosis and its implications for health-related quality of life
}

\author{
Fredrik Norström ${ }^{1 *}$, Lars Lindholm ${ }^{1}$, Olof Sandström ${ }^{1,2}$, Katrina Nordyke $^{1}$ and Anneli Ivarsson ${ }^{1}$
}

\begin{abstract}
Background: To determine how the delay in diagnosing celiac disease (CD) has developed during recent decades and how this affects the burden of disease in terms of health-related quality of life (HRQoL), and also to consider differences with respect to sex and age.

Methods: In collaboration with the Swedish Society for Coeliacs, a questionnaire was sent to 1,560 randomly selected members, divided in equal-sized age- and sex strata, and 1,031 (66\%) responded. HRQoL was measured with the EQ-5D descriptive system and was then translated to quality-adjusted life year (QALY) scores. A general population survey was used as comparison.
\end{abstract}

Results: The mean delay to diagnosis from the first symptoms was 9.7 years, and from the first doctor visit it was 5.8 years. The delay has been reduced over time for some age groups, but is still quite long. The mean QALY score during the year prior to initiated treatment was 0.66; it improved after diagnosis and treatment to 0.86, and was then better than that of a general population (0.79).

Conclusions: The delay from first symptoms to CD diagnosis is unacceptably long for many persons. Untreated CD results in poor HRQoL, which improves to the level of the general population if diagnosed and treated. By shortening the diagnostic delay it is possible to reduce this unnecessary burden of disease. Increased awareness of $\mathrm{CD}$ as a common health problem is needed, and active case finding should be intensified. Mass screening for CD might be an option in the future.

\section{Background}

Celiac disease $(\mathrm{CD})$ is a permanent intolerance to gluten found in wheat, rye and barley. Gluten induces an autoimmune reaction in the small intestinal mucosa resulting in inflammation, villous atrophy and malabsorption. The only effective treatment is a gluten-free diet, which usually leads to healing of the intestinal mucosa and recovery from signs and symptoms [1]. Living with untreated $\mathrm{CD}$ is associated with a risk for extensive negative health consequences [2,3]. In some individuals the gastrointestinal symptoms are obvious, but frequently the symptoms are vague, which complicates the identification of CD cases. This has been shown both by an average delay of 11-13 years from symptoms to diagnosis [4-6], and through screening studies. Screening studies have shown five to 10 undiagnosed cases for every diagnosed

\footnotetext{
* Correspondence: fredrik.norstrom@epiph.umu.se

'Department of Public Health and Clinical Medicine, Epidemiology and

Global Health, Umeå University, Umeå, Sweden

Full list of author information is available at the end of the article
}

case in some Western European countries [7], four of five Swedish adults with CD are undiagnosed [8], and two of three Swedish children with CD are undiagnosed [9]. In the latter study the prevalence was as high as $3 \%$, indicating that $\mathrm{CD}$ is more common in some populations than the often mentioned $1 \%$.

Health-related quality of life (HRQoL) as an aspect of living with $C D$ has been studied frequently [4,5,10-17], although several questions still remain. The two generic utility-based instruments, Short Form 36 (SF-36) and EuroQol 5 Dimensions instrument (EQ-5D), are often used to measure HRQoL. SF-36 includes eight multi-item measures that represent different aspects of health [18]. EQ-5D includes both a descriptive system, comprised of five health-related dimensions (mobility, self-care, usual activities, pain/discomfort and anxiety/depression) divided into three levels of severity, and a visual analogue scale (VAS) for recording overall health [19]. Both instruments can be translated to a quality-adjusted life year (QALY) score, which enables comparisons between different

\section{() Biomed Central}


diagnoses and with the general population. EQ-5D translation algorithms were first developed for the United States [20] and the United Kingdom (UK) populations [21], with the latter commonly used for the Swedish population [22]. For CD, SF-36 is still the most frequently used instrument [12,14-17], but EQ-5D has become increasingly popular $[5,10]$.

Studies on treated CD adults have shown divergent results, with HRQoL either similar to $[4,5,10]$ or worse than that of the general population $[14,17]$. Females with treated CD have been shown to experience worse HRQoL than males with treated CD [5,11-13]. One study using EQ-5D collected retrospective HRQoL data from members of a CD patient organization in the UK [5]. They concluded that the HRQoL before CD diagnosis is quantitatively similar to that of stroke patients, and that after initiated treatment it improved and was as good as that of the general population.

Despite many studies, unanswered questions remain, due in part to the small size of those studies. Previous studies have also lacked detailed analyses of various aspects due to the complex pattern regarding diagnostic delay and factors such as sex, age and time period for diagnosis. The aim of this study was to determine how the delay in diagnosing $\mathrm{CD}$ has developed during recent decades and how this affects the burden of disease in terms of HRQoL, and also to consider differences with respect to sex and age.

\section{Methods}

\section{Study design}

During 2009 we performed a cross-sectional questionnaire survey, of Swedish adults with CD that was approved by the Regional Ethical Review Board at Umeå University. The questionnaire was in Swedish and is accompanied to this article with an English translation [additional file 1]. For comparison, a questionnaire survey of the general adult population, "Health On Equal Terms" [23,24], was used. The latter was performed during 2006 and was approved by the ethical review board at the Swedish National Board of Health and Welfare.

\section{Study populations}

We studied members of the Swedish Society for Coeliacs in 2009. The society is open to people with CD and other food intolerances and is the only one of its kind in the country. When joining the society, members self-report their food intolerance. At the time of the study, the society had 15,659 members reporting CD, 11,094 of whom were 20 years of age or older. Ludvigsson and colleagues defined 29,096 individuals diagnosed with CD in Sweden, 26,047 who were still alive, between 1969 and 2008, based on biopsy information from a computerized search of all regional pathology departments [25]. Thus, the society most likely represents about $60 \%$ of all persons with CD in Sweden. The general adult population study consisted of the four most northern Swedish counties, with a population of 677,777 persons 20 years of age or older.

\section{Subjects}

In total, 1,560 adults with reported CD were invited to participate, with 65 males and females randomly selected from each five-year interval from 20 years of age and above (20-24, 25-29,..., 70-74, and 75 years or older). Out of 1,122 responders, 1,031 (66\%) were eligible for the study. A reported CD diagnosis based on medical expertise was required for inclusion. As this information was lacking in the society's register, when respondents stated that they had CD, questionnaire information was used to assess how their CD was diagnosed (blood sample, biopsy, and/or diet change), and if a medical professional had recommended adherence to a gluten-free diet. Ninety-one members did not meet eligibility requirements, and they comprised three criteria groups; i) they did not have CD $(\mathrm{n}=34)$, ii) CD diagnosis uncertain $(\mathrm{n}=$ 33), and iii) age and/or sex not consistent based on register information and questionnaire responses $(n=24)$. Those with uncertain CD were those reporting a selfdiagnosis or that a gluten-free diet had not been recommended by a medical professional. Of eligible responders, $52 \%(\mathrm{n}=536)$ were females and the mean age was 52 years (Table 1 ).

In the general population survey 37,912 randomly selected persons were invited in strata of age, sex, county and municipality. In total, 27,809 (73\%) responded, 25,797 of whom were 20 years or older [23]. Fifty-three percent $(n=13,781)$ were females and the mean age was 52 years.

\section{Questionnaires}

Questionnaires were administered by the Swedish Society for Coeliacs (CD population) and by Statistics Sweden (general population), both distributed by the postal service to the persons' homes. To facilitate responding in both studies, a prepaid envelope was included and three reminders were sent out when needed. Questionnaire responses were scanned and thereafter checked for consistency.

The CD questionnaire included a section on delay to $\mathrm{CD}$ diagnosis with questions about the first appearance of symptoms possibly related to $\mathrm{CD}$, the time of the first visit to a physician for those symptoms, and time of diagnosis. Information that could verify the $\mathrm{CD}$ diagnosis and self-reported degree of compliance with a gluten-free diet was also collected. We used the EQ-5D instrument to measure HRQoL. The respondent was asked about the year prior to initiated treatment for $C D$, referred to as pre-treatment, and about today, the time of responding to the questionnaire. The EQ-5D descriptive system was 
Table 1 Characteristics of celiac disease subjects

\begin{tabular}{|c|c|c|c|c|c|c|}
\hline & $n$ & $\%$ & Mean & Median & Qua & artile \\
\hline & & & & & $1 \mathrm{st}$ & 3rd \\
\hline Participants & 1,031 & & & & & \\
\hline Males & 495 & 48 & & & & \\
\hline Females & 536 & 52 & & & & \\
\hline Age when responding (years) & 1,031 & & 52 & 53 & 36 & 67 \\
\hline Duration to diagnosis (years) & & & & & & \\
\hline First symptom & 818 & & 9.7 & 4 & 1 & 14 \\
\hline First doctor visit & 853 & & 5.8 & 1 & 0 & 8 \\
\hline $\begin{array}{l}\text { Age at diagnosis for the whole } \\
\text { group }\end{array}$ & 945 & & 39 & 41 & 27 & 53 \\
\hline $0-19$ years & 162 & 17 & & & & \\
\hline 20-39 years & 292 & 31 & & & & \\
\hline $40-59$ years & 353 & 37 & & & & \\
\hline$\geq 60$ years & 138 & 15 & & & & \\
\hline $\begin{array}{l}\text { Age at diagnosis in relation to } \\
\text { period for diagnosis }\end{array}$ & & & & & & \\
\hline$<1980$ & 67 & & 17 & 2 & 1 & 37 \\
\hline 1980-1989 & 162 & & 27 & 32 & 1 & 45 \\
\hline 1990-1999 & 272 & & 39 & 43 & 30 & 52 \\
\hline $2000-2004$ & 221 & & 46 & 47 & 33 & 59 \\
\hline 2005-2009 & 444 & & 45 & 46 & 31 & 59 \\
\hline $\begin{array}{l}\text { Compliance with a gluten-free } \\
\text { diet }\end{array}$ & 1,025 & & & & & \\
\hline Strict & 979 & 96 & & & & \\
\hline Non-strict & 46 & 4 & & & & \\
\hline $\begin{array}{l}\text { Household member with celiac } \\
\text { disease }\end{array}$ & 117 & 11 & & & & \\
\hline Highest educational level & 1,013 & & & & & \\
\hline Primary school & 263 & 26 & & & & \\
\hline Secondary school & 414 & 41 & & & & \\
\hline University degree & 336 & 33 & & & & \\
\hline
\end{tabular}

answered completely by $779(76 \%)$ respondents and EQ VAS by 914 (89\%) respondents.

In the general population, the EQ-5D descriptive system was completely responded to by 24,460 persons $(95 \%)$ aged 20 years or more. EQ-VAS was not included in the questionnaire.

\section{Statistical analysis}

Descriptive statistics were presented using frequency tables, cross-tabulations, and mean and median values. Means were compared with Student's t-test. Delay to diagnosis was estimated as the difference between the year of the first symptoms indicative of $\mathrm{CD}$ and the reported year of diagnosis. For a response of no symptoms before diagnosis, the delay was defined as 0 years. The delay from the first doctor visit was estimated in a similar way. Dependency between the time period for CD diagnosis and the delay to diagnosis was analyzed with the Cox proportional hazards model [26]. An exponential of the hazard ratio above 1 implies a shorter delay from first symptoms to diagnosis compared to the baseline, which was a diagnosis before 1980. The descriptive system was translated to a QALY score using UK weights [21]. Linear regression was used to study determinants for the QALY score pre-treatment and today. These analyses included sex, current age, delay from first symptoms indicative of $\mathrm{CD}$ to diagnosis (cutoff set to 2 years), and time period for diagnosis. Statistical significance was defined at the $5 \%$ level. Microsoft Access was used for data handling, while Stata 11.2 (StataCorp LP, College Station, TX) was used for statistical analysis.

\section{Results}

\section{General characteristics}

Of the 1,031 respondents, $52 \%$ were females. Mean and median ages at diagnosis were 39 and 42 years, respectively. Strict compliance with a gluten-free diet was reported by 979 (96\%), and 117 (11\%) reported a household member with $\mathrm{CD}$ (Table 1).

\section{Delay to CD diagnosis}

The mean delay from the first symptoms indicative of $C D$ to diagnosis was 9.7 years and the median delay was 4 years (quartiles 1-14 years). From the first visit to a doctor due to $\mathrm{CD}$-related symptoms to diagnosis, the mean delay was 5.8 years and the median delay was 1 year (quartiles $0-8$ years) (Table 1 ). Both males and females had a mean of at least 9 years from the first symptoms to diagnosis for each 5-year age group from 35-39 up to 65-69 years (data not shown). Excluding those below 20 years, no age group had a shorter mean delay than 6 years.

The median delay from symptoms to $\mathrm{CD}$ diagnosis has increased during recent decades, from 1 year for those diagnosed before 1980, to 5 years if diagnosed during the period 2005-2009 (data not shown). However, between these time periods the median age at diagnosis has increased from 2 years to 46 years (Table 1). Actually, the delay has decreased for some age groups in recent decades (Figure 1). This shift in delay is statistically significant for both males and females aged 20-39 years, and for females aged 40-59 years diagnosed during the period 2000-2004 as compared to before 1990 (Table 2). However, the delay is still considerable; for example, in $2005-2009,56 \%$ of males and $47 \%$ of females aged 20-39 had a delay of at least 5 years (Figure 1). For the age groups 0-19 years and $>59$ years at diagnosis, no statistically significant differences were observed with respect to delay to diagnosis when comparing time periods (data not shown).

\section{Health-related quality of life}

Within the EQ-5D descriptive system the dimension anxiety/depression differed most negatively for untreated $\mathrm{CD}$ patients when compared with the general population (Table 3). The mean QALY score for the CD population 


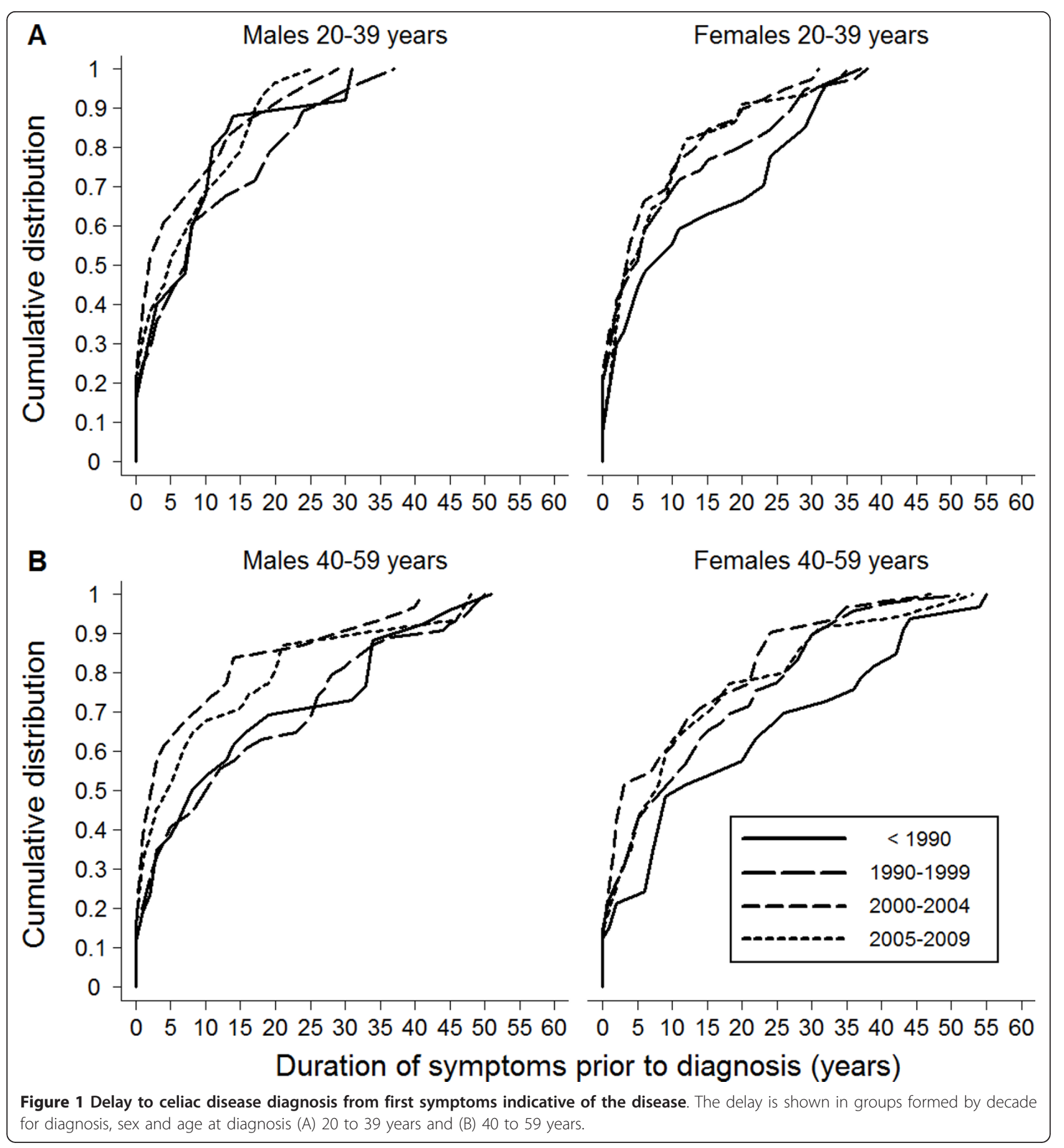

pre-treatment was 0.66 , and it had increased to 0.86 today $(\mathrm{p}<0.01)$ (Table 4). For the general population the score was 0.79 , thus lower than for treated CD patients. Females reported a significantly lower QALY score than males, both for the CD population pre-treatment and today (Figure 2), as well as in the general population $(\mathrm{p}<0.01)$. EQ VAS scores also improved after diagnosis $(p<0.01)$, with higher scores for $C D$ males than for CD females $(\mathrm{p}<0.01)$, both pre-treatment and today (Table 4).

Factors related to health-related quality of life

The QALY scores were significantly lower for CD females compared to CD males, both pre-treatment and today (Table 5). A lower QALY score pre-treatment was also associated with a younger current age, a long delay 
Table 2 Relationship between time period for diagnosis and delay from first celiac disease symptoms to diagnosis

\begin{tabular}{|c|c|c|c|c|c|c|c|c|}
\hline \multirow[b]{3}{*}{ Diagnosis year ${ }^{a}$} & \multicolumn{4}{|c|}{ Age $20-39$ years } & \multicolumn{4}{|c|}{ Age $40-59$ years } \\
\hline & \multicolumn{2}{|c|}{$\begin{array}{c}\text { Males } \\
(n=142)\end{array}$} & \multicolumn{2}{|c|}{$\begin{array}{l}\text { Females } \\
(n=148)\end{array}$} & \multicolumn{2}{|c|}{$\begin{array}{c}\text { Males } \\
(n=105)\end{array}$} & \multicolumn{2}{|c|}{$\begin{array}{c}\text { Females } \\
(n=150)\end{array}$} \\
\hline & $H^{b}$ & $\mathrm{Cl}^{\mathrm{C}}$ & HR & $\mathrm{Cl}$ & $\mathrm{HR}$ & $\mathrm{Cl}$ & HR & $\mathrm{Cl}$ \\
\hline$<1990$ & 1 & - & 1 & - & 1 & - & 1 & - \\
\hline 1990-1999 & 1.04 & $0.65-1.7$ & 1.58 & $1.0-2.5^{*}$ & 0.81 & $0.47-1.4$ & 1.29 & $0.78-2.1$ \\
\hline $2000-2004$ & 1.71 & $1.0-2.9^{*}$ & 1.91 & $1.2-3.2^{*}$ & 1.27 & $0.71-2.3$ & 1.70 & $1.0-2.8^{*}$ \\
\hline 2005-2009 & 1.36 & $0.80-2.3$ & 1.54 & $0.95-2.5$ & 1.20 & $0.69-2.1$ & 1.46 & $0.90-2.4$ \\
\hline
\end{tabular}

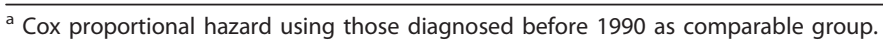

${ }^{b}$ Exponential of the hazard rate.

c Confidence interval.

* Significant difference at 5\% level compared to diagnosis before 1990.

between first symptoms and diagnosis (more than 2 years), and being diagnosed before 1990 as compared to being diagnosed more recently (1990-2004) (Table 5).

\section{Discussion}

CD patients experienced poor HRQoL pre-treatment, which improved significantly after diagnosis and treatment. Many experienced a long delay to diagnosis, both from the first symptoms and from the first visit to a doctor. It is promising that patients diagnosed after 2004 reported better HRQoL than those diagnosed earlier and that the delay in diagnosis has decreased during recent decades; however, many still experience too long a delay.
There has been a pronounced increase in median age at diagnosis, from 2 to 46 years in recent decades, illustrating that $\mathrm{CD}$ has changed from presenting as a childhood disease to being a disease affecting all ages.

This is a large study with a high response rate. A strength is that we used a validated HRQoL instrument and compared HRQoL for the CD population with that of a general population. The approach of asking CD respondents about HRQoL both before and after initiated $\mathrm{CD}$ treatment has only been tried once before [5]. Our study is unique in that results for males and females are presented separately, and there is a more thorough analysis of factors that affect HRQoL. Further, we add results

Table 3 EQ-5D descriptive system

\begin{tabular}{|c|c|c|c|c|c|c|}
\hline \multirow{3}{*}{ Dimensions } & \multicolumn{4}{|c|}{$\begin{array}{l}\text { Celiac disease } \\
\left(\mathrm{n}=779^{\mathrm{a}}\right)\end{array}$} & \multirow{3}{*}{\multicolumn{2}{|c|}{ 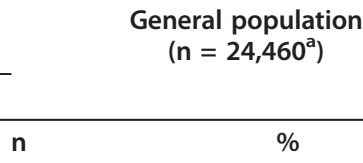 }} \\
\hline & \multicolumn{2}{|c|}{ Pre-treatment } & \multicolumn{2}{|c|}{ Today } & & \\
\hline & $\mathrm{n}$ & $\%$ & $\mathrm{n}$ & $\%$ & & \\
\hline \multicolumn{7}{|l|}{ Mobility } \\
\hline No problems & 720 & 92 & 737 & 95 & 20,899 & 85 \\
\hline Some problems & 50 & 6.4 & 41 & 5 & 3,496 & 14 \\
\hline Severe problems & 9 & 1.1 & 1 & 0.1 & 65 & 0.3 \\
\hline \multicolumn{7}{|l|}{ Self-care } \\
\hline No problems & 753 & 97 & 768 & 99 & 23,912 & 98 \\
\hline Some problems & 14 & 1.8 & 7 & 0.9 & 442 & 1.8 \\
\hline Severe problems & 12 & 1.5 & 4 & 0.5 & 106 & 0.4 \\
\hline \multicolumn{7}{|l|}{ Usual activities } \\
\hline No problems & 655 & 84 & 715 & 92 & 21,491 & 88 \\
\hline Some problems & 95 & 12 & 54 & 6.9 & 2,529 & 10 \\
\hline Severe problems & 29 & 3.7 & 10 & 1.3 & 440 & 1.8 \\
\hline \multicolumn{7}{|l|}{ Pain/discomfort } \\
\hline No problems & 291 & 37 & 481 & 62 & 9,484 & 39 \\
\hline Some problems & 319 & 41 & 278 & 36 & 13,658 & 56 \\
\hline Severe problems & 169 & 22 & 20 & 2.6 & 1,318 & 5.4 \\
\hline \multicolumn{7}{|l|}{ Anxiety/depression } \\
\hline No problems & 369 & 47 & 546 & 70 & 17,045 & 70 \\
\hline Some problems & 314 & 40 & 222 & 28 & 6,898 & 28 \\
\hline Severe problems & 96 & 12 & 11 & 1.4 & 517 & 2.1 \\
\hline
\end{tabular}

${ }^{a}$ Responded to all dimensions both pre-treatment and today. 
Table 4 Quality-adjusted life year (QALY) scores and EQ-VAS

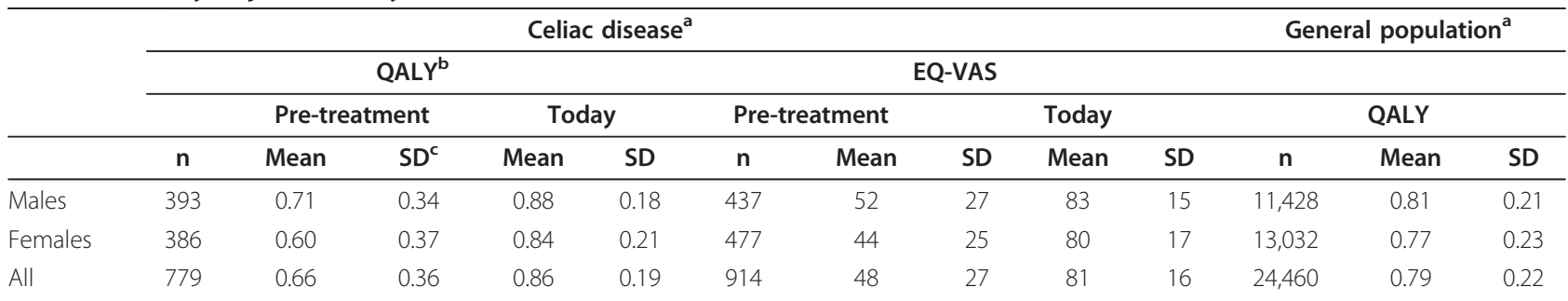

${ }^{a}$ Responded to all dimensions both pre-treatment and today.

${ }^{b}$ QALY scores were calculated from responses to the EQ-5D descriptive system.

c Standard deviation.

concerning how diagnostic delay has changed over time, also taking age and sex into consideration.

We believe that our findings are of great value for an increased understanding of how $\mathrm{CD}$ and its diagnostics affect people, despite some potential biases. We cannot be sure that our results are representative for the whole Swedish CD population. However, even if the results are only valid for responders (66\% of invited) to the questionnaire within our study population (members of the Swedish Society for Coeliacs which correspond to about $60 \%$ of Swedish adults with $C D$ ), they nevertheless show an experienced burden for a sample representing about $40 \%$ of Swedish adults with CD, irrespective of age. The general population in our study is limited to northern Sweden while the CD population comes from the entire country. However, regarding HRQoL, there was no statistical difference between persons with $\mathrm{CD}$ from the northern part of the country and the rest of Sweden. A recall bias might appear as some responders had their $\mathrm{CD}$ diagnosis long ago. This might cause both a low estimate of HRQoL pre-treatment, as well as an overestimate of the delay from first symptoms indicative of $C D$ to $C D$

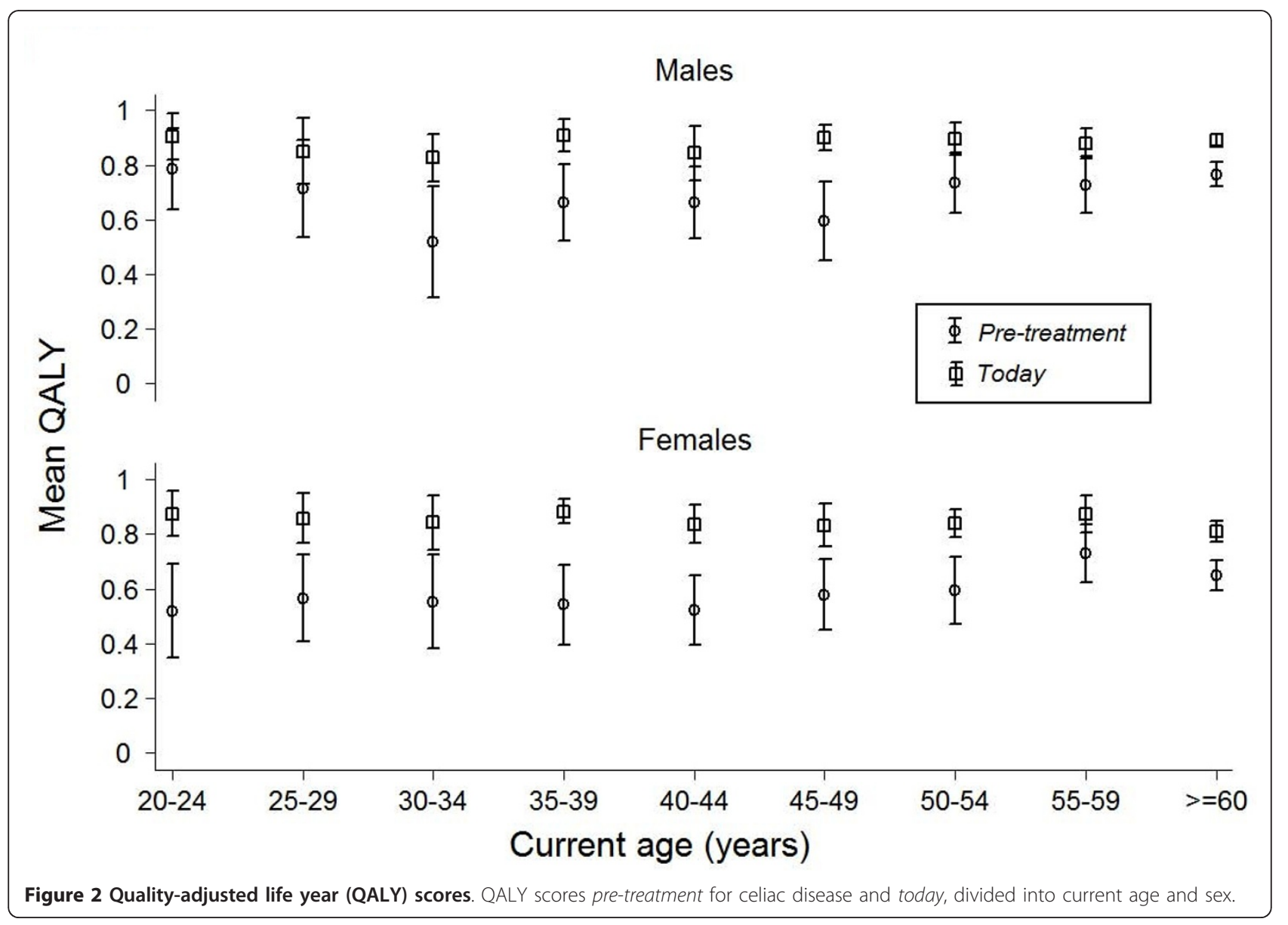


Table 5 Factors related to health-related quality of life (HRQoL) pre-treatment for celiac disease (CD) and today

\begin{tabular}{|c|c|c|c|c|}
\hline \multirow[b]{2}{*}{ Factor $^{\mathrm{a}}$} & \multicolumn{3}{|c|}{ Pre-treatment } & \multirow{2}{*}{$\begin{array}{l}\text { Today } \\
\mathrm{p}\end{array}$} \\
\hline & coeff. & $\mathrm{p}$ & coeff. & \\
\hline$S e x^{\mathbf{b}}$ & -0.10 & $<0.001$ & -0.046 & 0.003 \\
\hline Current age (years) & 0.0039 & $<0.001$ & -0.0003 & 0.513 \\
\hline Long delay ${ }^{c}$ & -0.14 & $<0.001$ & -0.013 & 0.397 \\
\hline Diagnosed 1990-1999 & 0.11 & 0.008 & 0.002 & 0.916 \\
\hline $2000-2004^{d}$ & 0.13 & 0.002 & -0.0008 & 0.971 \\
\hline $2005-2009^{d}$ & 0.06 & 0.142 & -0.011 & 0.615 \\
\hline Constant & 0.49 & $<0.001$ & 0.91 & $<0.001$ \\
\hline
\end{tabular}

${ }^{a}$ Linear regression analysis was performed to predict $\mathrm{HRQ}$ L, measured with quality-adjusted life year (QALY) scores, including those who responded to all five dimensions of EQ-5D pre-treatment and today $(n=624)$.

${ }^{\mathrm{b}}$ Males $=0$ and females $=1$.

' Delay to diagnosis from first symptoms indicative of CD $>2$ years.

${ }^{\mathrm{d}}$ Comparing with those diagnosed before 1980

diagnosis. However, the usual recall pattern is to report fewer episodes of ill health, and therefore previous health problems might instead be underestimated.

A long diagnostic delay has been shown earlier in several studies [4-6]. However, awareness of CD has increased in recent decades and serological testing has been introduced and improved. Similar to findings in our study, a shortened diagnostic delay over time was found in the UK [5], but was not observed in Canada [4]. Neither study considered increasing age at diagnosis, a factor that might affect their results as well.

The positive effects of diagnosis and treatment we report here are also supported by others $[5,10]$. Our results confirm that $\mathrm{CD}$ females experience a lower HRQoL than males [13]. The difference is even larger before initiated treatment, which indicates that living with untreated $\mathrm{CD}$ might be a greater burden for females. It is also interesting that treated $C D$ patients reported a better HRQoL than the general population. This might be a result of an altered frame of reference, after experiencing poorer health, or due to adapting to a healthier life style after being diagnosed with a chronic disorder. Our study subjects reported an unexpectedly high rate of compliance with a gluten-free diet (96\%), and it has been shown that better compliance is related to a better HRQoL $[11,17,27]$.

Despite increased awareness in society and in health care, many $C D$ cases will be missed due to vague symptoms. Mass screening for $\mathrm{CD}$ has been raised as a possible option [28]. CD mass screening fulfils most of the listed criteria for a medical mass screening adapted by WHO from Wilson and Jungner [29]. However, knowledge concerning the natural history of $\mathrm{CD}$ and the cost-effectiveness of a CD mass screening is lacking $[28,30,31]$. There are few health economic evaluation studies of a CD mass screening. Existing studies indicate that a screening might be cost-effective [32,33], and that parents' willingness to pay for a CD mass screening on average is greater than the screening cost [34]. It was recently estimated in the United States that the medical cost for clinically detected CD patients is reduced by $\$ 1764$ the year following diagnosis as compared to the average cost during the preceding years [35]. The fact that both cost savings and long-term health complications might differ between clinically diagnosed patients and screening detected CD must be taken into account, and there is a need for studies on this particular group [36,37].

\section{Conclusion}

Our study shows that for many individuals there is an unacceptably long delay from the first symptoms to $C D$ diagnosis. Untreated CD results in poor HRQoL that is improved to the level of the general population if diagnosed and treated. By shortening the diagnostic delay it is possible to reduce this unnecessary burden of disease. Increased awareness of $\mathrm{CD}$ as a common health problem is needed, and active case finding should be intensified. Mass screening for $\mathrm{CD}$ might be an option in the future.

\section{Additional material}

Additional file 1: Questionnaire-To you, a member of the Swedish

Society for Coeliacs. Your experience is important!.

\section{Acknowledgements}

We thank all those who responded to the questionnaire, and the Swedish Society for Coeliacs for their assistance in improving the questionnaire and their crucial administrative help. In relation to the construction of the questionnaire we also thank Professor Alastair Gray and his research team at the University of Oxford. The study was undertaken at the Umeå Centre for Global Health Research at Umeå University.

\section{Author details}

${ }^{1}$ Department of Public Health and Clinical Medicine, Epidemiology and Global Health, Umeå University, Umeå, Sweden. ${ }^{2}$ Department of Clinical Sciences, Pediatrics, Umeå University, Umeå, Sweden.

\section{Authors' contributions}

Study design by FN, Al, LL, and KN. FN coordinated data acquisition. FN performed the analyses and the interpretation in collaboration with $\mathrm{Al}, \mathrm{LL}$, and OS. FN drafted the paper and all co-authors contributed actively. All authors read and approved the final manuscript.

\section{Competing interests}

The authors declare that they have no competing interests.

Received: 9 August 2011 Accepted: 7 November 2011 Published: 7 November 2011

\section{References}

1. Di Sabatino A, Corazza GR: Coeliac disease. Lancet 2009, 373:1480-1493.

2. Cosnes J, Cellier C, Viola S, Colombel JF, Michaud L, Sarles J, Hugot JP, Ginies JL, Dabadie A, Mouterde O, et al: Incidence of autoimmune diseases in celiac disease: Protective effect of the gluten-free diet. Clin Gastroenterol Hepatol 2008, 6:753-758. 
3. Rubio-Tapia A, Kyle RA, Kaplan EL, Johnson DR, Page W, Erdtmann F, Brantner TL, Kim WR, Phelps TK, Lahr BD, et al: Increased prevalence and mortality in undiagnosed celiac disease. Gastroenterology 2009, 137:88-93.

4. Cranney A, Zarkadas M, Graham ID, Butzner JD, Rashid M, Warren R, Molloy M, Case S, Burrows V, Switzer C: The Canadian celiac health survey. Dig Dis Sci 2007, 52:1087-1095.

5. Gray AM, Papanicolas IN: Impact of symptoms on quality of life before and after diagnosis of coeliac disease: results from a UK population survey. BMC Health Serv Res 2010, 10:105.

6. Green PHR, Stavropoulos SN, Panagi SG, Goldstein SL, McMahon DJ, Absan H, Neugut Al: Characteristics of adult celiac disease in the USA: Results of a national survey. Am J Gastroenterol 2001, 96:126-131.

7. Fasano A, Catassi C: Current approaches to diagnosis and treatment of celiac disease: An evolving spectrum. Gastroenterology 2001, 120:636-651.

8. Ivarsson A, Persson LÅ, Juto P, Peltonen M, Suhr O, Hernell O: High prevalence of undiagnosed coeliac disease in adults: a Swedish population-based study. J Intern Med 1999, 245:63-68.

9. Myléus A, Ivarsson A, Webb C, Danielsson L, Hernell O, Högberg L, Karlsson E, Lagerqvist C, Norström F, Rosén A, et al: Celiac disease revealed in 3\% of Swedish 12-year-olds born during an epidemic. J Pediatr Gastroenterol Nutr 2009, 49:170-176

10. Casellas F, Lopez Vivancos J, Malagelada JR: Perceived health status in celiac disease. Rev Esp Enferm Dig 2005, 97:794-804.

11. Casellas F, Rodrigo L, Lopez Vivancos J, Riestra S, Pantiga C, Baudet JS, Junquera F, Puig Divi V, Abadia C, Papo M, et al: Factors that impact health-related quality of life in adults with celiac disease to multicenter study. World J Gastroenterol 2008, 14:46-52.

12. Hallert C, Granno C, Grant C, Hulten S, Midhagen G, Strom M, Svensson H, Valdimarsson T, Wickstrom T: Quality of life of adult coeliac patients treated for 10 years. Scand J Gastroenterol 1998, 33:933-938.

13. Hallert C, Sandlund O, Broqvist M: Perceptions of health-related quality of life of men and women living with coeliac disease. Scand J Caring SCi 2003, 17:301-307.

14. Häuser W, Gold J, Stein J, Caspary WF, Stallmach A: Health-related quality of life in adult coeliac disease in Germany: results of a national survey. Eur I Gastroenterol Hepatol 2006, 18:747-754.

15. Johnston SD, Rodgers C, Watson RGP: Quality of life in screen-detected and typical coeliac disease and the effect of excluding dietary gluten. Eur J Gastroenterol Hepatol 2004, 16:1281-1286.

16. Nachman F, Maurino E, Vazquez H, Sfoggia C, Gonzalez A, Gonzalez V, Plancer del Campo M, Smecuol E, Niveloni S, Sugai E, et al: Quality of life in celiac disease patients: prospective analysis on the importance of clinical severity at diagnosis and the impact of treatment. Dig Liver Dis 2009, 41:15-25.

17. Usai P, Minerba L, Marini B, Cossu R, Spada S, Carpinello B, Cuomo R, Boy MF: Case control study on health-related quality of life in adult coeliac disease. Dig Liver Dis 2002, 34:547-552.

18. McHorney CA, Ware JE, Lu JFR, Sherbourne CD: The MOS 36-item shortform health survey (SF-36). III. Tests of data quality, scaling assumptions, and reliability across diverse patient groups. Med Care 1994, 32:40-66.

19. Brooks R: EuroQol: The current state of play. Health Policy 1996, 37:53-72.

20. Shaw JW, Johnson JA, Coons SJ: US valuation of the EQ-5D health statesDevelopment and testing of the D1 valuation model. Med Care 2005, 43:203-220.

21. Dolan P: Modeling valuations for EuroQol health states. Med Care 1997, 35:1095-1108.

22. Burström $K$, Johannesson $M$, Diderichsen $F$ : Swedish population healthrelated quality of life results using the EQ-5D. Qual Life Res 2001, 10:621-635.

23. Wadman C, Boström G, Karlsson A-S: Health on equal terms? Results from the 2006 Swedish National Public Health Survey. [http://www.fhi.se/ PageFiles/4351/A2008_1_health\%20on\%20equal\%20terms.pdf].

24. Hälsa på lika villkor? En undersökning om hälsa och livsvillkor i Sverige 2006. [http://www.fhi.se/Documents/Statistik-uppfoljning/Folkhalsoenkaten/ Enkatformular-LISTA/Formular-nationell-2006.pdf].

25. Ludvigsson JF, Montgomery SM, Ekbom A, Brandt L, Granath F: Smallintestinal histopathology and mortality risk in celiac disease. JAMA 2009, 302:1171-1178

26. Cleves MA, Gould WW, Gutierrez RG: An introduction to survival analysis using stata. College Station, Texas: Stata Press; ${ }_{\text {in }}$ Revised 2004.
27. Hauser W, Stallmach A, Caspary WF, Stein J: Predictors of reduced healthrelated quality of life in adults with coeliac disease. Aliment Pharmacol Ther 2007, 25:569-578.

28. Mearin ML, Ivarsson A, Dickey W: Coeliac disease: is it time for mass screening? Best Pract Res Clin Gastroenterol 2005, 19:441-452.

29. Wilson JMG, Jungner G: Principles and practice of screening for disease. WHO Chron 1968, 22:473.

30. Hoffenberg EJ: Should all children be screened for celiac disease? Gastroenterology 2005, 128:S98-S103.

31. Collin P: Should adults be screened for celiac disease? What are the benefits and harms of screening? Gastroenterology 2005, 128:S104-S108.

32. Hershcovici T, Leshno M, Goldin E, Shamir R, Israeli E: Cost effectiveness of mass screening for coeliac disease is determined by time-delay to diagnosis and quality of life on a gluten-free diet. Aliment Pharmacol Ther 2010, 31:901-910.

33. Shamir R, Hernell O, Leshno M: Cost-effectiveness analysis of screening for Celiac disease in the adult population. Med Decis Making 2006, 26:282-293.

34. Norström F, Ivarsson A, Lindholm L, Carlsson A, Danielsson L, Högberg L, Karlsson E, Löfgren C: Parents' willingness to pay for coeliac disease screening of their child. J Pediatr Gastroenterol Nutr 2011, 52:452-459.

35. Long KH, Rubio-Tapia A, Wagie AE, Melton L, Lahr BD, Van Dyke CT, Murray JA: The economics of coeliac disease: a population-based study. Aliment Pharmacol Ther 2010, 32:261-269.

36. Evans KE, McAllister R, Sanders DS: Should we screen for coeliac disease? No. Br Med J 2009, 339:b3674.

37. Kumar PJ: Antagonist-European and North American populations should be screened for coeliac disease. Gut 2003, 52:170-171.

\section{Pre-publication history}

The pre-publication history for this paper can be accessed here: http://www.biomedcentral.com/1471-230X/11/118/prepub

\section{doi:10.1186/1471-230X-11-118}

Cite this article as: Norström et al:: Delay to celiac disease diagnosis and its implications for health-related quality of life. BMC Gastroenterology 2011 11:118.

\section{Submit your next manuscript to BioMed Central and take full advantage of:}

- Convenient online submission

- Thorough peer review

- No space constraints or color figure charges

- Immediate publication on acceptance

- Inclusion in PubMed, CAS, Scopus and Google Scholar

- Research which is freely available for redistribution

Submit your manuscript at www.biomedcentral.com/submit
Ciomed Central 